\title{
Scholarship Reconsidered: Considerations for a More Inclusive Scholarship in the Academy
}

\section{Jepkorir Rose Chepyator-Thomson and Susan Elizabeth King}

\begin{abstract}
The current scholarship model in higher education has been conceived, produced, and reproduced in the image of the dominant culture. The values, behaviors, and expectations for the academy have been forged by a university culture that is "relatively homogeneous by race, ethnicity, and gender." Although ethnic racial minorities are outnumbered by both white females and males, white males, by virtue of their numbers in rank and other positions of power, are the dominant members of the academic community. Individuals whose characteristics differ from those of the dominant group members are less likely to receive recognition, sponsorship, favorable procedural evaluation, or positive commentary on their scholarship. The purpose of this paper is to discuss considerations for a more inclusive scholarship in the academy.
\end{abstract}

Universities and colleges, like all other social institutions in society, are highly bureaucratic and hierarchical and cater to the needs and wants of the capitalistic society of the United States. Society's needs determine, for the most part, the behavior and the rewards of individuals within these institutions (Collins, 1977). Schooling in the United States has evolved to meet the needs of capitalistic employers who require a disciplined and skilled labor force and to provide a mechanism for social control (Bowles, 1977). Education shapes the minds of the future work force and, in turn, conditions social and cultural relationships outside educational institutions (Carnoy \& Levin, 1985). The demand for a highly trained work force and expert knowledge for efficient social functioning has heightened the role of higher institutions in the postindustrial society of the US. Universities and colleges are expected to respond to local, state, and national economic development, and the focus has been to increase the capacity of individuals and organizations to produce goods and services that create wealth (Cote \& Cote, 1993), especially for the people who control the means of production.

Jepkorir Rose Chepyator-Thomson is with the Department of Physical Education and Sport at the State University of New York, Brockport, NY 14420. Susan Elizabeth King is with the Department of Health, Physical Education, and Recreation at the University of Kansas, Lawrence, KS 66045. 


\section{Institutions of Higher Learning: Historical Development and Emergent Role in Society}

Universities were originally conceived as places where the search for greater knowledge and understanding was considered paramount. In recent times, universities, rather than being places where professors and their clients search for knowledge and engage in intellectual inquiry for its own sake (Bok, 1990), have become instruments of cultural and social change. They are no longer considered as places detached from society, existing solely for the advancement of knowledge and uninfluenced by the social and cultural values of society at large.

Unlike their European counterparts, U.S. colleges and universities have existed historically as centers for undergraduate instruction, designed to train individuals to meet the needs of industry, agriculture, and technology (Cote \& Cote, 1993; Geiger, 1990). Indeed, the society of the US supported its colleges and universities for the instruction they provided students. The universities paid their faculty for such social service through public funds and student fees. Few universities focused on the advancement of knowledge and its dissemination through publication (Geiger, 1990).

Following World War II, colleges and universities mushroomed. The federal government began funding scientific research within universities, and research work became part of the university's function. Higher education institutions have since functioned as sources of (a) new knowledge discovery important to the nation, (b) science-based inventions helpful to the national defense, and (c) technological innovations responsive to our economy and to the changing needs of our society (Bok, 1990). The recent appearance of research foci, as well as the university's dependence on external funding, have drawn higher education institutions away from their original mission of basic undergraduate instruction. According to Geiger (1990), universities have become research institutions for various reasons: to retain the loyalties of faculty, to provide public service to state and federal government, and to enhance institutional prestige. The university's focus on research has fulfilled the critical function of mediating between the knowledge demands of society at large and the knowledge-producing capabilities of the university faculty (Bok, 1990). In the current state of affairs, higher education institutions, of all the social institutions in society, may be said to have occupied a central role in our postindustrial society.

\section{The Present Scholarship Model}

Universities and colleges are heavily governed by capitalist principles and as such, are subject to capitalist direction and function. Amassing capital by any means necessary has been as much a part of higher education as it is a part of the larger society. In keeping with the capitalist ideology, faculty sell their labor to their respective institutions, be it in the form of teaching, service, or research. In the present scholarship model, research work done by faculty brings the most recognized rewards for one's labor, hence the current dominance of research-based work in higher education.

Research foci, now firmly rooted in the work performed in many universities, have steered many faculty away from teaching and service duties. Many faculty have oriented their functions toward contributing to the knowledge-base of 
their respective disciplines. In response to this change, universities now evaluate faculty members' scholarship based on their research productivity. According to Metzler (1994), academic groups and institutions place a high value on scholarship; thus, a faculty member's goal for advancement and for winning institutional rewards is largely tied to his or her scholarship productivity. Research production as measured by the number of publications in prestigious journals has been determined, for the most part, by the use of a recognition and reward system that is becoming more problematic than ever before in our history. Evidence of scholarship is demonstrated by one's "physical representation of scholarly knowledge" in published articles (Metzler, 1994, p. 443). This "monolithic system" of demonstrating scholarship productivity has led to the mad rush for more and more papers for publication, making scholarship like a "currency" and making the published articles like "icons" (Metzler, 1994, pp. 442-443).

\section{"Valid" Scholarship: Theoretical Underpinnings}

Scholarship production is the primary vehicle by which individuals advance their careers (Johnsrud, 1991). The question of interest here is, what constitutes "valid" forms of scholarship? We contend that the current scholarship model has been conceived, produced, and reproduced in the image of the dominant culture. Indeed, the values, behaviors, and expectations for the academy have been forged by a university culture that is "relatively homogeneous by race, ethnicity, and gender" (Menges \& Exum, 1983, p. 186). Approximately three-quarters of all full-time college faculty are males (73\%) and whites (89\%), and ethnic minorities only comprise $11 \%$ of all full-time faculty (Russell, 1991). Although ethnic racial minorities are outnumbered by both white females and males, white males, by virtue of their numbers in rank and other positions of power, are the dominant members of the academic community (Russell, 1991). A report by the American Association of University Professors indicates that women are disproportionately found in the lower ranks, and minimal progression is shown through the hierarchical system in higher education (Lomperis, 1990). For instance, 68\% of men and only 38\% of women were tenured in research and doctoral institutions in the early 80 s (Russell, 1991).

In occupying positions of power and prestige in the academic community, white males have become an occupational status group. According to Max Weber (1971), a status group consists of individuals who share a "specific, positive or negative, estimation of honor"; a particular "style of life is expected from those who wish" to join (Thompson \& Tunstall, 1971, pp. 256-257). Prestige, power, and status order develop on the basis of external status characteristics such as race and gender (Ridgeway \& Berger, 1986). Those with the external characteristics of the dominant group receive higher status, and those without such characteristics are given lesser status and power. The individuals with higher status set the criteria used in a faculty member's evaluation, and they determine a person's rise in the status order.

Performance expectations of the academy are "culturally associated" with certain status characteristics that include race and gender. From an expectation states theory perspective, "group members form performance expectations for themselves ... [and these expectations have] become the basis for the distribution of rewards, power, and prestige" (Ridgeway \& Berger, 1986, p. 604). Since 
performance expectations are designed and shared by members of the dominant group, primarily white males, they have assumed "a collective normative quality" (Ridgeway \& Berger, 1986, p. 614).

Expectation states theory explains, in part, the demographics of higher education. White males as a collective group, not as individuals, determine performance expectations that will subsequently be used to demonstrate an individual's capacity "to make useful contributions" to the academy (Ridgeway \& Berger, 1986, p. 604) . Indeed, as a status group within the academy, white males determine what ideas are of most worth and therefore "rule as thinkers, as producers of ideas, and regulate the production and distribution of the ideas of their age. Consequently their ideas are the ruling ideas of the age" (Max Weber, 1963).

It is therefore theorized that in institutions of higher education, rewards, power, and prestige are distributed or withheld based upon an individual's attributes as well as performance. Individuals whose characteristics differ from those of the dominant group members are less likely to receive recognition, sponsorship, favorable procedural evaluation, or positive commentary on their scholarship. The expectations for superior or inferior performance may be determined by such characteristics as race and gender; thus an inferior performance may be anticipated from an individual who is different from the members of the dominant group. When performance expectations are high for certain individuals, they are more likely to receive opportunities to contribute to the knowledge-base of their discipline and to receive positive evaluations for their contributions. This, in turn, will make them influential members in the decision-making process of the group.

The literature indicates that women and people of color are small in number within the academy. White males continue to dominate positions of power and, consequently, have determined and continue to determine the performance expectations for the entire academy. The reconsideration of scholarship represents an emerging contestation of groups vying for status and power. The scholarly contributions of women and people of color have been viewed as marginal; thus, few women and people of color have climbed the ladder of professorship successfully. Unless scholarship is reconsidered, researchers and writers from nondominant groups will continue to operate from a "disadvantaged, external status position" (Ridgeway \& Berger, 1986). Therefore, there is a need for a drastic change in the academic reward system.

\section{Scholarship Reconsidered: Current Considerations for Reform}

Current considerations for reforming scholarship call for service to society and social-problems-based foci in research (Boyer \& Hechinger, 1981); faculty-student collectivity in knowledge generation, bearing human problems (Shore, 1992); and scholarship that meets the ever-changing mission of higher education (Carlisle, 1991) in rewarding the professorate for tenure and promotion. Boyer (1987) argues for a broader term of scholarship, "one that brings legitimacy to [the] full scope of academic work" (p. 16). Gray, Froh, and Diamond (1992) advocate, based on Boyer's research, a modification of tenure and promotion to recognize and reward teaching because teaching, research, and service have not been given equal merit either historically or currently in the academy. According to Gray et al. (1992), those involved with the present system believe the current reward system needs to have a balance between research and teaching. For ex- 
ample, Gray et al. (1992) have indicated that the state of Virginia has put forth its support for more weight to be given to teaching and for the development of a promotion and tenure process that utilizes a balance between research and teaching for various faculty.

Boyer's 1990 view suggests four ways to reform scholarship in higher education. These include the scholarship of discovery, integration, application, and teaching. The scholarship of discovery is product oriented and centers on the expansion of basic knowledge and the creation of new ideas and theories in a discipline. This form of scholarship allows faculty to confront the unknown and to contribute to human knowledge production (Boyer, 1990). The scholarship of integration focuses on the reinterpretation of knowledge such that connections between varying disciplines are revealed and given meaning. This involves giving new meaning or insight to original research (Boyer, 1990). In the scholarship of application, knowledge is used to solve problems in a consistent manner, thus providing appropriate and necessary service to the university and society at large. This type of scholarship focuses on a scholarly service that is tied to "one's special field of knowledge" and that contributes to the developments of new understandings (Boyer, 1990, pp. 22-23). In reference to the scholarship of teaching, the knowledge acquired from the previous forms of scholarship are utilized to transform and expand students' knowledge base for effective functioning in a society. This kind of scholarship allows for the development of knowledge categories that help "build bridges between the teachers' understanding and student learning" (Boyer, 1990, p. 23).

Metzler's (1994) "vision for the future" has called for new ways to reward diverse activities as scholarship in the academy. The expanded view of scholarship advocated by Metzler (1994) centers on Boyer's (1990) four-part reconsideration of scholarship and his own, the scholarship of engagement. Metzler terms this new version of scholarship the "Boyer plus one model" (Metzler, 1994, p. 453). Metzler (1994) explains that the scholarship of engagement focuses on faculty members' assumption of leadership roles, and changes are made accordingly in their areas of expertise. These areas include institutional, professional, and public forums in which knowledge and expertise inform and influence people's opinions in appropriate ways.

Boyer's and Metzler's expansions of scholarship are quite considerable; however, the dominant culture still pervades every area of knowledge production and dissemination. The scholarships of discovery and integration, generally considered investigative forms of scholarship, are the most respected scholarly efforts and are largely determined by the dominant culture.

Another perspective on the reconsideration of scholarship in the academy has been advocated by Koch (1994). Koch proposes a weighting system that gives a faculty member a specified number of points for each of the categories of scholarship: teaching, research productivity, and service. Depending on the kind of university one currently sells his or her services to, a faculty member may put a substantial weight on research productivity if he or she works in a research-based institution, or place an equal emphasis on both research and teaching if that is what the institution requires. One's service contributions would get an equal weight if one works in a slightly more teaching-oriented research or a teaching-based institution. At a research-based institution, service would be given a weight of zero. Koch (1994) believes professional preparation and activities; teaching 
ability; scholarly production; and service to institution, profession, and community should be considered and valued in the evaluation of a faculty member's scholarship. Koch proposes that workshop participation, editorial work, newsletter contributions, research notes, book reviews, presentations, and publication in nonrefereed journal/magazines should constitute scholarly/professional activities.

Although the current developments in the reform of traditional scholarship are quite considerable, white males' perspectives of reality still receive enormous credence in published work, in teaching, and in other scholarly or professional activities. Although one may argue that there is a free will in the behavioristic model that has underguarded higher education to date, one has only to look at the historical development of institutions to note that such an idea has not materialized in reality. Whose lenses then are to be used to reconsider scholarship in higher education?

\section{Scholarship Reconsidered: A Call for a More Inclusive Scholarship}

Women and people of color have had a minimal impact on the production of knowledge considered of most value in higher education. Indeed, their scholarship has had little representation in journals of elite- and mass-based readership. Further, their scholarship activities have occupied a peripheral role in the running of macro- and microservice operations and in the research production of faculty. In specific terms, the academic milieu in higher education does not favor, for example, black educational researchers interested in addressing issues facing minorities and the disadvantaged (Frierson, 1990). Furthermore, black faculty get minimal or no support in their research endeavors and receive little scholarly recognition for focusing their research on minority populations (Frierson, 1990). Additionally, women's knowledge production and dissemination are not adequately represented in research and in public-service operations. Therefore, the present scholarship model is exclusive in nature as it continues to reproduce the ideals of the dominant culture with only cursory consideration of diverse perspectives in many areas of reality. The scholarship criteria used in promotion and tenure have largely been determined by the politico-administrative elite and the powerful university intelligentsia of white establishment. As few women and people of color have received tenure and promotion, there is a need for a drastic change in the way the rewards of promotion and tenure are awarded in the academy-hence our call for a more inclusive scholarship.

\section{Culture and Diversity in Scholarship Reconsidered}

The expansion of basic knowledge and the discovery of new ideas and theories in all areas of human intellectuality depend on who is doing the thinking and whose lenses are being used. It is our contention that diverse cultural lenses need to be used in creating knowledge structures that come to bear in definitions, concepts, and theories in the scholarship of discovery, integration, application, and teaching, as well as engagement. In addition, women and people of color need to play a much greater role than ever before in all areas of scholarship because they bring more varied interests and concerns to white male-dominated academy.

Women and people of color tend to be interested in social reform, grass-roots change efforts, and long-term collaborative work for the purpose of connecting 
theory and practice. Many women and people of color are compelled to use their scholarly expertise to uplift other members of their race and/or gender; to solve social, economic, and educational problems; and to make research useful not only for the academic elite but also for the masses. Currently, they are reluctant to conduct scholarly projects in these areas of concern because their project designs or results do not fit the scholarly model deemed acceptable by white males and are "not easily or appropriately evaluated by traditional measures" (Exum, 1983, p. 395). Their efforts are generally dumped into the category of "service," a catch-all term that encompasses any activity that does not result in a publication.

According to Boyer (1990), scholarship needs to be defined "in ways that respond more adequately to the urgent new realities both within the academy and beyond" (p. 3). Higher education performs a "diversity of functions" (Boyer, 1990, p. xii) that impact the larger community. Therefore, recognition of public service productions in scholarship reconsidered should be paramount. The "public service productions" constitute "service artifacts" such as technical manuals, training manuals, reports, and legal briefs derived from "service activities" that include presentations, consultation, conferences and forums, planning and development meetings, exercise of teaching, training, and coaching (Wagner, 1993, p. 698). The public-service productions may further be divided into macroservice and microservice, depending on whether the information reaches a mass audience or limited audience respectively.

\section{Diversify Political Structures Acting as Determinants of the Promotion and Tenure Process}

Since women and people of color are numerically small in numbers, they are often judged solely by white male colleagues who occupy positions of power and status in the academy. The political structures that act as determinants of promotion and tenure represent the bureaucratic channels that a faculty's portfolio must pass through for evaluation purposes. Who makes up the body responsible for determining one's fate in higher education? The social and cultural structures in operation in higher education do not favor women and people of color; hence the various bodies responsible for determining who gets promotion and tenure should have a fair representation of women and people of color and also other people of nondominant culture orientation. We argue that it is not enough to have incentive and reward systems that recognize diversity in scholarship production and dissemination; we need to acknowledge the fact that the persons who discuss the quantification and qualification of that scholarship need to be representative of the people being evaluated for promotion and tenure.

\section{Provide Support for Diverse Scholarship}

Knowledge creation among women and people of color needs to be facilitated in the academic community. But first and foremost, the university administration must commit itself to the hiring and subsequent tenure of diverse persons. A substantial cohort of women and people of color will provide individual scholars with the "psychological safety associated with numbers" (Frierson, 1990, p. 13), a much needed social and professional support, and opportunities for networking and collaboration with scholars who share their interests. Frierson (1990) 
lists "the advantages [of] networking within the professional mainstream" as follows:

collaborating on or participating in funded research projects; increased opportunities for joint authorship on manuscripts of various types; increased opportunities for paid consulting; regular invitations to participate in symposia or panels at professional meetings; having one's name circulated for serious consideration for attractive professional positions; serving on editorial boards, major committees of professional organizations, major boards or commissions, and so forth. (p. 13)

Without a strong network of colleagues, women and people of color miss the benefits that white males currently enjoy as a result of their having opportunities to freely network among their cultural counterparts-the powerful and well-connected members of the academic elite.

Women and minority scholars will also benefit from support in the form of reduced service responsibilities. For instance, the university administration needs to curb the role of nontenured faculty in institutional and departmental governance during the probationary period. In comparison to their white colleagues, minority professors are generally overburdened with obligations to committees that require minority representation and "special interest" student organizations, in addition to their responsibilities to peers, departments, and administrators. Although these duties preclude consistent research conduction, a faculty member who declines to perform such duties in order to focus on research

runs the risk of incurring negative sanctions as not being a "good citizen" and not living up to the service and community expectations (openly stated or not) of minority students, white faculty peers, or administrators. (Exum, 1983, p. 395)

Therefore, a reduction in service responsibilities will decrease the role conflict experienced by women and people of color and will facilitate scholarly production among diverse persons.

University administrators should also support diverse scholarship through the provision of financial (grants, start-up money) and technical support (e.g., equipment, software). In the absence of funds and other types of professional support, efforts to study issues of interest to women and people of color are stunted, resulting in reduced opportunities for individuals to write and publish in these areas. Above all, the university administration needs to consider formal and informal support systems for persons advocating diverse cultural and social foci in knowledge construction and dissemination.

In conclusion, considerations for reform in higher education, in terms of research, teaching, and service, have come at a critical time in our history. The current political climate in higher education and in society at large does not advocate diversity, particularly cultural diversity relating to ethnic minorities and women. There is an urgent need to rethink the methods by which the professional performance of faculty is evaluated and rewarded. The three-tier ranking system--assistant, associate, and full professorship-represents a class structure in which one's movement up the hierarchy is determined by a scholar's ability to market his or her services to those who have power and influence over one's upward social mobility. Historically, this has been accomplished through a reward structure based on the 
dominant culture's perspective. The designation of the term scholar is bestowed upon individuals who perform university duties such as conducting research or publishing in mainstream journals, to the satisfaction of (and in the image of) the academic elite. We contend that the scholarly "template," the standard by which we are all judged, is exclusive in nature. Those who do not fit, due to alternate beliefs, interests, and methodology, are tossed aside. How long can universities afford to permit the loss of such vast numbers of academic talent?

The current call for the consideration of diverse perspectives in research, teaching, and service must be treated as paramount in higher education. The winds of change and academic discontent that have swept through the country in recent times have necessitated such an effort. Indeed, there needs to be a drastic reconstruction of the power structure in the academy, and in turn, the society at large such that diverse voices may be heard either through knowledge production in research, dissemination of knowledge in teaching, or the performance of service duties. In the reconsideration of scholarship, all professorial duties should be judged on the basis of their value to the university and local community, as well as the nation, regardless of mode or medium.

As we move into the next century, can institutions of higher learning look beyond the current backlash against affirmative action policies that were created to end discrimination against women and minorities in the workforce? Or will they succumb to political pressures from the powerful elite and retreat to the "good old days" before affirmative action when, based solely upon race, persons were hired, fired, promoted, or demoted at the whim of their superiors? Some believe that the United States can now embrace a "colorless" society, one in which men and women rise through the ranks, or fall through the cracks, on their own merit. We strongly believe that this country is not ready to take such a step. Therefore, we challenge the university intelligentsia to lead the way by rising above the political war being waged by those who seek to retain power, by moving toward an academy that consists of a mosaic of scholars who seek to research, teach, or serve in the interests of our diverse population.

\section{References}

Bok, D. (1990). Universities and the future of America. Durham, NC: Duke University Press. Bowles, S. (1977). Unequal education and the reproduction of labor. In J. Karabel \& A. H. Halsey (Eds.), Power and ideology in education (pp. 137-153). New York: Oxford University Press.

Boyer, E. (1987). College: The undergraduate experience in America. New York: Harper \& Row. Boyer, E. (1990). Scholarship reconsidered. Princeton, NJ: Carnegie Foundation for the Advancement of Teaching.

Boyer, E., \& Hechinger, F. (1981). Higher learning in the nation's service. Washington, DC: Carnegie Foundation for the Advancement of Learning.

Carlisle, P. (1991, October). Crisis in the reward system. Blacksburg, VA: Virginia Tech, Office of the Provost.

Carnoy, M., \& Levin, H. (1985). Schooling and work in the democratic state. Stanford, CA: Stanford University Press.

Collins, R. (1977). Functional and conflict theories of educational stratification. In J. Karabel \& A.H. Halsey (Eds.), Power and ideology in education (pp. 118-136). New York: Oxford University Press. 
Cote, L.S., \& Cote, M.K. (1993). Economic development activity among land-grant institutions. Journal of Higher Education, 64(1), 55-73.

Exum, W.H. (1983). Climbing the crystal stair: Values, affirmative action, and minority faculty. Social Problems, 30(4), 383-399.

Frierson, H.T., Jr. (1990). The situation of Black educational researchers: Continuation of crisis. Educational Researcher, 19(2), 12-17.

Geiger, R.L. (1990). Organized research units-their role in the development of university research. Journal of Higher Education, 61, 1-19.

Gray, P., Froh, B., \& Diamond, R. (1992). A national study of research universities on the balance between research and undergraduate teaching. Syracuse University, NY: Center for Instructional Development.

Jackson, K.W. (199l). Black faculty in academia. In P.G. Altbach \& K. Lomotey (Eds.), The racial crisis in American higher education (pp. 135-148). Albany: State University of New York Press.

Johnsrud, L.K. (1991). Administrative promotion. The power of gender. Journal of Higher Education, 62, 119-149.

Koch, W. (1994). Common evaluation goals with unique faculty roles in higher education. The Chronicle of Higher Education in Physical Education, 6(1), 1, 11.

Lomperis, A.M.T. (1990). Are women changing the nature of the academic profession? Journal of Higher Education, 61, 643-677.

Menges, R.J., \& Exum, W.H. (1983). Barriers to the progress of women and minority faculty. Journal of Higher Education, 54, 123-144.

Metzler, M.W. (1994). Scholarship reconsidered for the professorate of 2010. Quest, 46, 440-455.

Ridgeway, C.L., \& Berger, J. (1986). Expectations, legitimation, and dominance behavior in task force groups. American Sociological Review, 51, 603-617.

Russell, S.H. (1991). The status of women and minorities in higher education. Findings from the 1988 national survey of post-secondary faculty. CUPA Journal, 42(1), 1-11.

Shore, P. (1992). The myth of the university. Lanham, MD: University Press of America.

Thomson, K., \& Tunstall, J. (Eds.). (1971). Sociological perspectives. London: Penguin Books.

Wagner, J. (1993). Social contracts and university public service: The case of agricultural schooling. Journal of Higher Education, 64, 696-729.

Weber, M. (1963). Existence and consciousness. In K. Thompson \& J. Tunstall (Eds.), Sociological perspectives (pp. 46-49). London: Penguin Books.

Weber, M. (1971). Class, status, and party. In K. Thompson \& J. Tunstall (Eds.), Sociological perspectives (pp. 250-264). London: Penguin Books. 
Copyright of Quest (00336297) is the property of Human Kinetics Publishers, Inc. and its content may not be copied or emailed to multiple sites or posted to a listserv without the copyright holder's express written permission. However, users may print, download, or email articles for individual use. 